\title{
THE OXYGEN TRANSFER PROCESS ON SOLID OXIDE/NOBLE METAL ELECTRODES, STUDIED WITH IMPEDANCE SPECTROSCOPY, $d c$ POLARIZATION AND ISOTOPE EXCHANGE
}

\author{
B. A. Boukamp, B. A. van Hassel, I. C. Vinke, K. J. de Vries and A. J. Burggraaf \\ University of Twente, Department of Chemical Technology, Laboratory of Inorganic Chemistry, \\ Materials Science and Catalysis, P.O. Box 217, 7500 AE Enschede, The Netherlands
}

\author{
(Received 10 March 1993)
}

\begin{abstract}
The electrochemical oxygen transfer process at the yttria stabilized zirconia (YSZ) and Feimplanted YSZ, and at the erbia stabilized bismuth oxide (BE25) surface is studied with dc polarization and impedance spectroscopy using gold electrodes, and with ${ }^{18} \mathrm{O}$ gas phase exchange. The surface modification by Fe-implantation increases the exchange current density up to a factor of 50, but analysis of the impedance spectra at different polarization levels indicates that the type of electrode reaction is not changed by the implantation. Inductive effects at cathodic polarizations are interpreted with a stepwise transfer of electrons. Isotope exchange experiments show an increase in adsorption/reaction sites at the surface after implantation. The high exchange current density, $I_{0}$, for BE25 is independent of type of electrode but does depend on electrode morphology. $I_{0}$ can be equated to the surface oxygen exchange rate, indicating that the entire electrolyte surface is active in the electrode exchange process. Qualitative interpretation of the impedance spectra measured at different levels of polarization results in a model where adsorbed oxygen species diffuse over the oxide surface, while charge transfer occurs across the surface.
\end{abstract}

Key words: electrode impedance, oxygen isotope exchange, oxygen electrode kinetics, erbia stabilized delta-bismuth oxide, yttria stabilized zirconia.

\section{INTRODUCTION}

The performance of oxygen-ion conducting devices, such as oxygen pumps, solid oxide fuel cells and semi-permeable oxide membranes, depends not only on the (partial-) ionic conductivity of the bulk oxide but also on the rate of exchange of oxygen at the ambient/solid-oxide interface. For many applications the thickness of the solid oxide is decreased as much as possible (to several microns or less) in order to decrease ohmic losses and thus improve efficiency. But as a result the surface oxygen exchange reaction will remain as the rate limiting step in the oxygen transfer process. Hence it is of importance to understand the oxygen exchange processes in order to be able to minimize the electrode polarization. The polarization behaviour is studied using $d c$ currentvoltage measurements in a three electrode arrangement. If charge transfer is the rate limiting process then the polarization curves will show ButlerVolmer behaviour:

$$
I=I_{0}\left[\exp \left(\frac{\alpha_{\mathrm{a}} F \eta}{R T}\right)-\exp \left(-\frac{\alpha_{\mathrm{a}} F \eta}{R T}\right)\right]
$$

where the charge transfer coefficients, $\alpha_{a}$ and $\alpha_{c}$, depend on the electrode reaction mechanism[1] (with $\sum \alpha=n / v, n$ is the number of electrons transferred, $v$ is the stoichiometry number of the rate determining step). Extrapolating the anodic and cathodic Tafel slopes to zero potential yields the exchange current density, $I_{0}$, which is equal to the equilibrium anodic and cathodic currents which flow without electrochemical gradient. If mass transport (diffusion) is the rate limiting step then again a Butler-Volmer type equation may apply, but the charge transfer coefficients and the exchange current density will have an "apparent" character $[2,3]$, ie they do not represent the coefficients of the local electrochemical reaction.

Using the stable ${ }^{18} \mathrm{O}$ isotope the surface oxygen exchange rate can be measured with a mass spectrometer by monitoring the gas phase ${ }^{18} \mathrm{O}$ ratio during the exchange experiment[4] or by SIMS analysis after exchange[5]. These measurements are performed at thermodynamic equilibrium (ignoring possible isotope effects), hence the equilibrium exchange fluxes of oxygen are measured. These fluxes are thus identical to the electrochemically derived cathodic and anodic exchange currents. If, for the electrode measurements, the electro-active area is known then the exchange current density, $I_{0}$ (in $\mathrm{A} \mathrm{cm}^{-2}$ ), can be equated to the overall surface oxygen exchange rate (in $\mathrm{mol} \mathrm{cm}^{-2} \mathrm{~s}^{-1}$ ), $r_{\mathrm{s}}[5]$ :

$$
I_{0}=4 F r_{3} \text {. }
$$

This requires of course that the electrochemical exchange process occurs mainly at the oxide surface. If the adsorption and dissociation of oxygen takes place at the noble metal electrode (eg porous Pt on yttria stabilized zirconia) then a large discrepancy between $I_{0}$ and $r_{3}$ will be observed [5].

The oxygen exchange process consists of a series of "reaction steps": adsorption of oxygen, dissociation and incorporation into the bulk lattice. Electron transfer may take place at any of these steps. With the oxygen isotope exchange technique it is possible to discern two major overall steps $[6,7]$ : (i) 
adsorption and dissociation of gas phase oxygen and (ii) the incorporation of atomic oxygen into the bulk. These steps are characterized by the rate constants $r_{\text {dis }}$ and $r_{\text {bulk }}$ with:

$$
r_{\mathrm{s}}=\left(r_{\mathrm{dis}}^{-1}+r_{\mathrm{bulk}}^{-1}\right)^{-1} \text {. }
$$

These reaction rates can be obtained from the time dependence of the ratios of mass-32 $\left({ }^{16} \mathrm{O}_{2}\right)$, mass-34 $\left({ }^{16} \mathrm{O}^{18} \mathrm{O}\right)$ and mass-36 $\left({ }^{18} \mathrm{O}_{2}\right)$ in the gas phase. It is then possible to indicate whether the dissociation of oxygen is the rate limiting step or that the incorporation into the lattice is rate determining. Measurement of the $P_{\mathrm{O}_{2}}$ dependence then can provide information on the involvement of electronic states and surface defects on these reaction steps[7].

Measurement of the dispersion of the electrode impedance also gives insight in the processes involved in the overall electrode reaction. If the time constants, associated with the separate reaction steps, differ significantly in magnitude a well resolved impedance spectrum will be observed. Quite often, however, this will not be the case. The electrode dispersion may then be analyzed using modern complex nonlinear least squares (CNLS) data analysis programs[8-10]. An "equivalent circuit" is then used as modeling function in the fit procedure. Unfortunately, the interpretation is not always straightforward as the circuit parameters may contain combinations of the reaction rate constants.

Impedance measurements at various levels of cathodic and anodic polarization, ie under current carrying conditions, will reveal the polarization dependence of the equivalent circuit elements. As the equivalent circuit is not necessarily a "one-to-one projection" of the separate reaction steps and rates, it can be difficult to arrive at a quantitative model which accurately describes the oxygen exchange process. The combination of the above mentioned techniques, however, will form a powerful research tool in the investigation of the oxygen exchange reaction.

This technique is not restricted to (noble) metal electrodes on solid electrolytes, but should be equally successful in the study of the exchange process on thin mixed conducting (ionically and electronically) oxide electrode layers on top of oxygen conducting solid electrolytes, eg for application in solid oxide fuel cells.

In this paper recent results are presented on the oxygen exchange process on two very different oxide ion conducting ceramics. Yttria stabilized cubic zirconia (YSZ) is one of the most commonly used oxygen conductors. For this material the electrode polarization is strongly dependent on the type of noble metal electrode used[11]. In an attempt to create a mixed conducting surface layer the electrolyte was implanted with $15 \mathrm{keV} F e[12,13]$. The properties of the porous gold/implanted layer electrode are compared with the properties of porous gold on non-implanted YSZ. In these studies presented here gold was specifically chosen as electrode, as gold is rather inert with respect to the dissociative adsorption of oxygen.

Erbia stabilized $\delta$-bismuth oxide $(25 \mathrm{~mol} \%$ erbia, abbreviated BE25) is one of the best oxygen ion conducting compounds known. Also, bismuth contain- ing compounds are well known for their catalytic activity in oxidation reactions which may be connected to the high surface oxygen exchange rate[4, 5]. For this material the electrode properties of porous gold are compared with the properties of porous $\mathrm{Pt}$ and with co-pressed gold gauze electrodes.

\section{MATERIALS AND SAMPLE PREPARATION}

\section{Yttria stabilized zirconia}

From yttria stabilized cubic zirconia powder $\left(13 \mathrm{~mol} \% \mathrm{YO}_{1.5}\right.$, Zircar) dense ceramic boules $\left(\rho_{\text {rel. }}\right.$ $99 \%$ ) were pressed and sintered following standard techniques[12]. From these boules disks were cut of approximately $1 \mathrm{~cm}$ diameter and $0.1 \mathrm{~cm}$ thickness. All samples received a final polish with $3 \mu \mathrm{m}$ diamond paste.

\section{Implantation of YSZ}

The YSZ samples were implanted on one side with $15 \mathrm{keV}{ }^{56} \mathrm{Fe}$ at a dose of $8 \times 10^{16}$ at $\mathrm{cm}^{-2}[12,13]$. An aluminium mask was used to give the implanted area an annular shape. Rutherford back scattering (RBS) and TEM analysis[13] showed an amophous surface layer of about $20 \mathrm{~nm}$ deep with a maximum Fe cation ratio of 0.5 . Upon annealing at $673 \mathrm{~K}$ in air all iron was oxidized to the $\mathrm{Fe}^{3+}$ state[14]. Ion scattering spectroscopy (ISS)[13] indicated that the implanted surface was covered by a thin layer $(\approx 2 \mathrm{~nm})$ if $\mathrm{Fe}_{2} \mathrm{O}_{3}$. Sputtered porous gold electrodes were applied on the implanted area using the same procedure as for the non-implanted reference YSZ samples.

Conductivity experiments were performed on thin layers of YSZ, sputtered on an alumina substrate[15]. Comparing the conductivity of $15 \mathrm{keV}$ Fe-implanted layers with $50 \mathrm{keV}$ Fe-implanted layers (buried Fe-profile) indicated that the electronic conductivity was mainly due to the $2 \mathrm{~nm}$ thin $\mathrm{Fe}_{2} \mathrm{O}_{3}$ surface layer[13], which is only present on the $15 \mathrm{keV}$ implanted samples.

\section{Erbia stabilized $\delta$-bismuth oxide}

Erbia stabilized bismuth oxide with $25 \mathrm{~mol} \%$ $\mathrm{Er}_{2} \mathrm{O}_{3}$ was prepared through a co-precipitation route[16]. After calcination boules were pressed and sintered. From these boules $\left(\rho_{\text {rel }}>99 \%\right)$ ceramic disks were cut of approximately 1.2 diam. and $0.15 \mathrm{~cm}$ thickness. The disks were polished with $\mathrm{Al}_{2} \mathrm{O}_{3}$ powder with a final grain size of $1 \mu \mathrm{m}$. Annular shaped gold electrodes were applied by sputtering $500 \mathrm{~nm}$ gold onto the samples followed by heat treatment in order to give the electrode an open appearance. For the co-pressed gold gauze electrode system an annular shaped gauze was pressed together with the BE25 powder in a steel die. After sintering the buried gauze was brought to the surface by careful grinding of the surface. As counter electrode porous sputtered gold was applied on all samples. A gold point was used as reference electrode.

\section{The gold/YSZ electrode system}

Electrode polarization. Polarization curves for the $\mathrm{O}_{2,8}, \mathrm{Au} / \mathrm{Fe}-\mathrm{YSZ}$ and the reference $\mathrm{O}_{2.8}, \mathrm{Au} / \mathrm{YSZ}$ electrodes are quite similar in shape. The cathodic 
(oxygen incorporation reaction) polarization is larger than the anodic one. Charge transfer coefficients of $\alpha_{c} \approx 0.5$ and $\alpha_{a} \approx 1.5-2.3$ were typically observed $[17,18]$. The exchange current density for the $\mathrm{O}_{2,8}, \mathrm{Au} / \mathrm{Fe}-\mathrm{YSZ}$ system was, however, up to a factor 50 larger than for the YSZ-reference, see the Tafel plot of Fig. 1.

Impedance spectroscopy. The electrode impedances for the $\mathrm{O}_{2,8}, \mathrm{Au} / \mathrm{Fe}-\mathrm{YSZ}$ and the $\mathrm{O}_{2,8}, \mathrm{Au} / \mathrm{YSZ}$ systems are also similar in shape and are dominated by a slightly depressed semicircle, attributed to the double layer (pseudo-) capacitance, $C_{\mathrm{dl}},[17,18]$. For large cathodic polarizations, $\eta<-0.1 \mathrm{~V}$, a negative loop develops at the low frequency end of the dispersion. In Fig. 2 examples are presented of the polarization dependent electrode impedance for the Fe-implanted electrode. For high anodic levels,

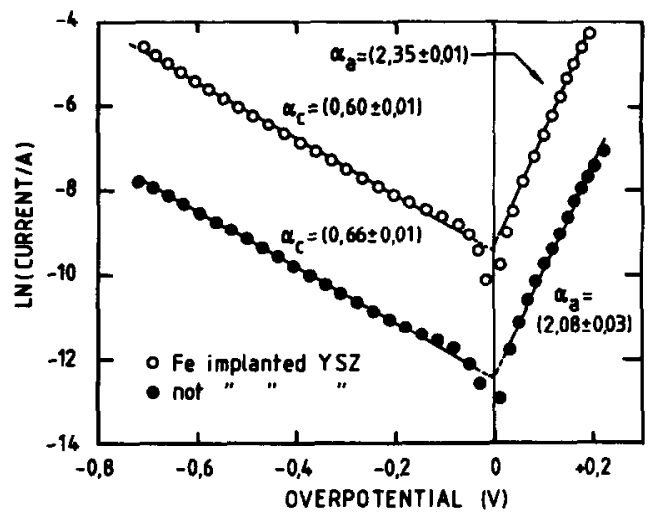

Fig. 1. Tafel plot of the polarization curves for the $\mathrm{O}_{2,8}$, $\mathrm{Au} / \mathrm{Fe}-\mathrm{YSZ}$ and the $\mathrm{O}_{2}, \mathrm{Au} / \mathrm{YSZ}$ electrode systems measured at $1024 \mathrm{~K}$ and $P_{\mathrm{O}_{2}}=1 \mathrm{~atm}$.

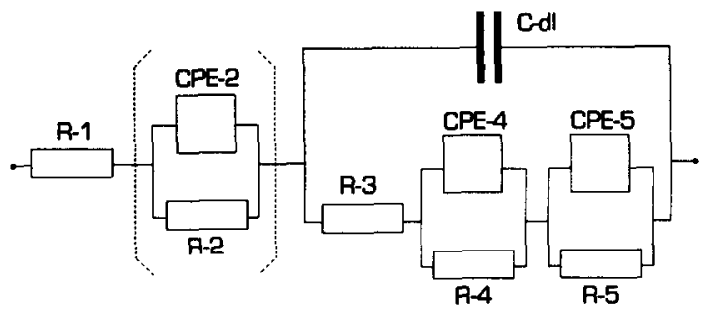

Fig. 3. General equivalent circuit used in the NLLS-fit analysis of the $\mathrm{Au} / \mathrm{YSZ}$ based electrode systems. The parallel $C P E_{2}-R_{2}$ circuit, placed between brackets, was only observed for the Fe-implanted electrodes.

$\eta>0.1 \mathrm{~V}$, also a small inductive loop appears at the low frequency end. All spectra could be resolved using the impedance analysis program Equivalent Circuit $[10,19]$ using the equivalent circuit of Fig. 3 as basis for the model functions. The sub-circuit placed between dashed brackets (Fig. 3) was observed exclusively for the Fe-implanted samples. This sub-circuit gives a small but significant contribution to the high frequency end of the electrode dispersion. It is tentively attributed to the interface between the amorphous Fe-YSZ layer and the crystalline matrix[18].

In the equivalent circuit of Fig. 3, $R_{3}$ is interpreted as the charge transfer resistance, $R_{\mathrm{c}}$, while the subcircuit $\left(R_{4}, C P E_{4}\right)\left(R_{3}, C P E_{5}\right)$ is attributed to the electrode reaction. The sub-circuit $R_{5}-C P E_{5}$ becomes insignificant at low polarization levels. Depending on the polarization level, frequency dependencies in the order of $(\omega)^{0.5}$ or $(\omega)^{-0.5}$ were observed for $C P E_{4}$ and $C P E_{5}$. This indicates that the reaction rate also depends on the diffusion of the adsorbed species.
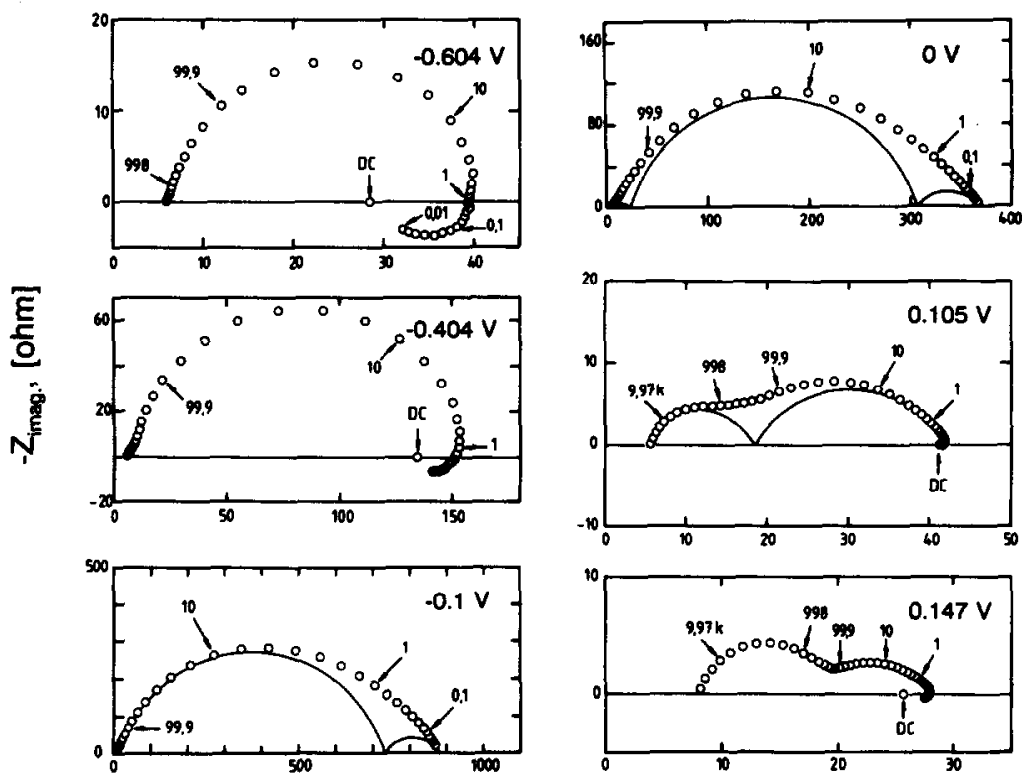

$Z_{\text {roal, }}$ [ohm]

Fig. 2. Impedance diagrams for the $\mathrm{O}_{2, \ldots}, \mathrm{Au} / \mathrm{Fe}-\mathrm{YSZ}$ electrode system as function of polarization, measured at $1024 \mathrm{~K}$ and $\boldsymbol{P}_{\mathrm{O}_{2}}=1 \mathrm{~atm}$. Frequencies are in $\mathrm{Hz}$. Drawn semi-circles represent contributions to the dispersion of the separate sub-circuits. 


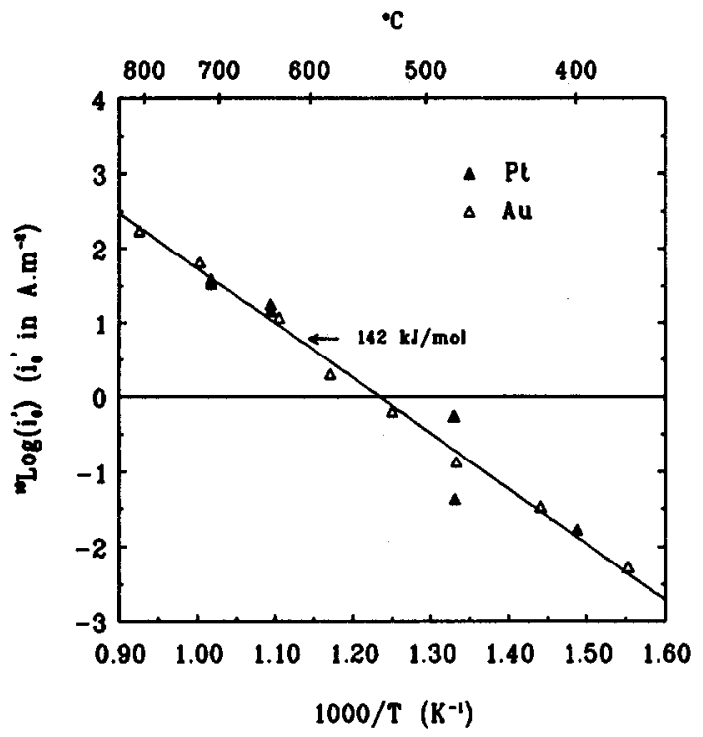

Fig. 4. Arrhenius plot of the exchange current densities for the sputtered gold and sputtered platinum electrodes on BE25.

Isotope exchange. The surface oxygen exchange rate, $r_{s}$, for yttria stabilized zirconia is very low. An exchange experiment on a solid sample at $1033 \mathrm{~K}$ $\left(P_{\mathrm{O}_{2}}=0.25 \mathrm{~atm}\right)$ indicates a value of 0.4 $3 \times 10^{-10} \mathrm{~mol} \mathrm{~cm}^{-2} \mathrm{~s}^{-1}$ measured by dynamic SIMS which is in reasonable agreement with values published by Steele et al.[5]. The exchange rate is too low to allow gas phase analysis during exchange[20]. The implantation of Fe does increase the exchange rate significantly, at the same tem-

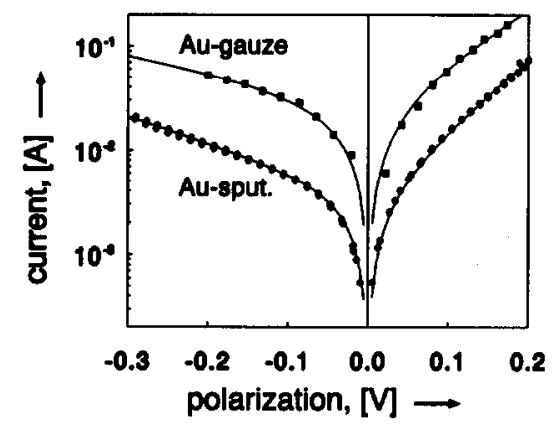

Fig. 5. Tafel plot of the polarization curves for the sputtered gold (1066 K) and co-pressed gold gauze (992 K) electrodes on BE25, measured in air.
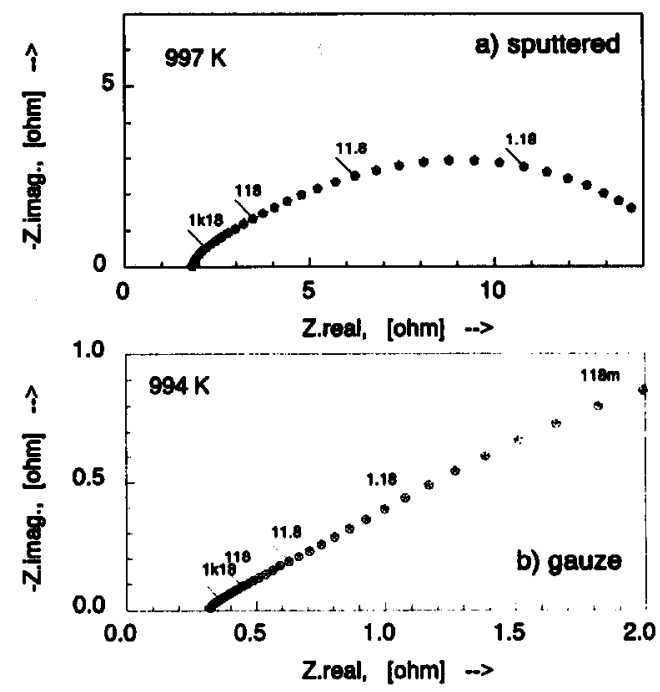

Fig. 6. Electrode impedance of a sputtered gold electrode (top) and of a co-pressed gold gauze electrode (bottom) on BE25, measured in air. Stars represent data, circles fit results, frequencies indicated are in $\mathbf{H z}$.

perature and pressure a value of 5$6 \times 10^{-9} \mathrm{~mol} \mathrm{~cm}^{-2} \mathrm{~s}^{-1}$ is found for $r_{8}$ from dynamic SIMS analysis while gas phase measurement during exchange yields $2.3 \times 10^{-9} \mathrm{~mol} \mathrm{~cm}^{-2} \mathrm{~s}^{-1}[20]$, which is about a factor of 10 larger than the exchange flux calculated from $I_{0}$.

\section{Stabilized $\delta$-bismuth oxide}

Electrode polarization. The polarization curves for the sputtered Pt and Au electrodes on BE25 are similar in shape and magnitude. In order to obtain the actual polarization $\eta$, the applied potential must be corrected for the "uncompensated" electrolyte resistance[21]. The cathodic polarization is larger than the anodic polarization, as was also observed for the $\mathrm{Au} / \mathrm{YSZ}$ system. The cathodic charge transfer coefficient, $\alpha_{c}$, is typically about 0.5 , the anodic coefficient, $\alpha_{\mathrm{a}}$, ranges between 1 and 2.5 for the Au electrode, depending on temperature and $\boldsymbol{P}_{\mathrm{O}_{2}}$ [22]. For the Pt electrode $\alpha_{a}$ scatters around 1. The exchange current densities, $I_{0}$, for the Pt and the Au electrodes are virtually identical (Fig. 4), despite the large difference in electrode morphology (Table 1). Hence on this electrolyte the electrode reaction cannot be limited to a small area at the three-phase boundary (TPB) line, as the TPB for Pt is about a factor 14 larger than for the $\mathrm{Au}_{\text {sput. }}$ electrode.

Table 1. Comparison of the electrode morphologies of the sputtered gold, sputtered platina and co-pressed gold gauze electrodes on BE25 (except for the three-phase line length, all other estimated values are relative)

\begin{tabular}{lcccc}
\hline Electrode type & $\begin{array}{c}\text { Three-phase } \\
\text { line/mm }\end{array}$ & $\begin{array}{c}\text { Electrolyte/electrode } \\
\text { contact }\end{array}$ & $\begin{array}{c}\text { Electrolyte/gas } \\
\text { ambient area }\end{array}$ & $\begin{array}{c}\text { Electrode/gas } \\
\text { ambient area }\end{array}$ \\
\hline Au sputtered & $1.4 \times 10^{5}$ & 0.83 & 0.17 & 0.86 \\
Pt sputtered & $1.2 \times 10^{6}$ & 0.64 & 0.36 & 0.80 \\
Ratio $\mathrm{Au}_{\text {spp }} / \mathrm{Pt}_{\text {sp }}$ & 0.12 & 1.3 & 0.47 & 1.1 \\
Au gauze & $1.0 \times 10^{4}$ & 0.65 & 0.65 & 0.35 \\
Ratio $\mathrm{Au}_{\text {spp }} / \mathrm{Au}_{\text {op }}$ & 14 & 1.28 & 0.26 & 2.46 \\
\hline
\end{tabular}




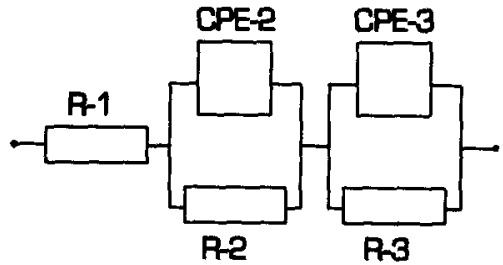

Fig. 7. Equivalent circuit used in the NLLS-fit analysis of the Au/BE25 electrode systems. For the co-pressed gold gauze electrode a Warburg was used for $C P E_{3}$.

The co-pressed gold gauze $\left(A u_{\text {geuzz }}\right)$ electrode shows very similar polarization behaviour, but $I_{0}$ is larger as can be seen in the Tafel plot of Fig. 5, while the $\alpha_{a}$ value scatters largely around 1[23]. Again the difference in morphology between $\mathrm{Au}_{\mathrm{enuze}}$ and $\mathrm{Au}_{\mathrm{sput}}$. (Table 1) indicates that the electrode reaction is not limited to the TPB.
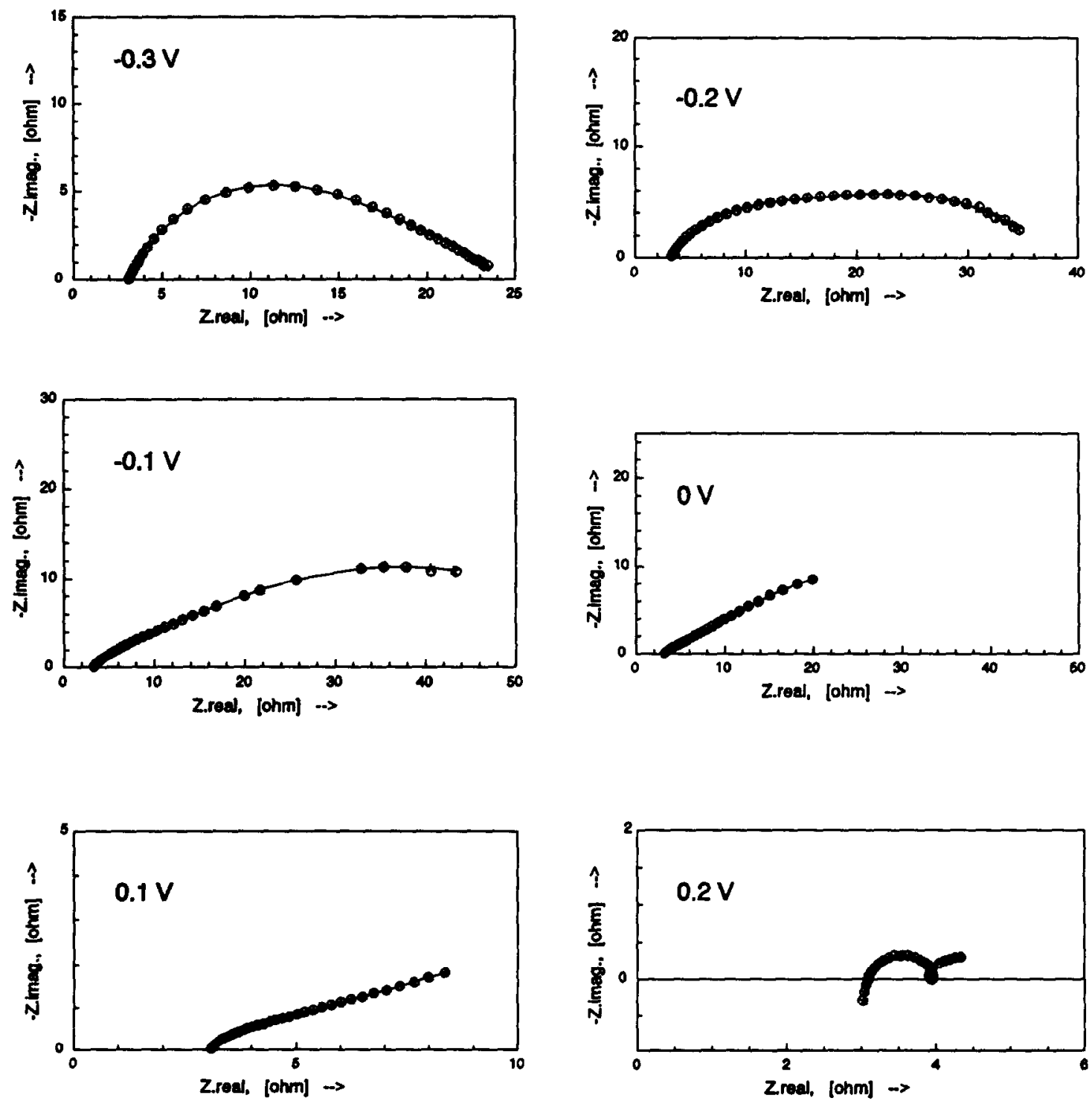

Fig. 8. Impedance diagrams for the Au _. /BE25 electrode system as function of polarization, measured at $859 \mathrm{~K}$ in air.

Impedance spectroscopy. Figure 6 shows typical electrode dispersions, measured in air, for the $\mathrm{Au}_{\mathrm{sput}}$. and the $\mathrm{Au}_{\text {gaure }}$ electrodes on BE25. A pronounced double layer (pseudo) capacitance is not observed. Careful analysis with the NLLS-fit program $[9,19]$ indicates the presence of at least two time constants. The equivalent circuit presented in Fig. 7 was found to give consistently the best fit results. For the $\mathrm{Au}_{\text {enuze }}$ electrode the second CPE element could be replaced consistently by a Warburg (CPE with $n=0.5$ or semi-infinite diffusion element). The frequency exponent of $C P E_{1}$ varied mostly between 0.25 end 0.5 , also indicating a diffusion step. The $Y_{0}$ value for the gauze electrode is about a factor 10 larger than found for $C P E_{2}$ of the sputtered electrode, this effect is quite apparent in Fig. 6 if one compares the position of the frequency marks in the dispersions.

The change of the dispersion as function of the polarization is presented in Fig. 8 for the $\mathrm{Au}_{\text {guuze }}$
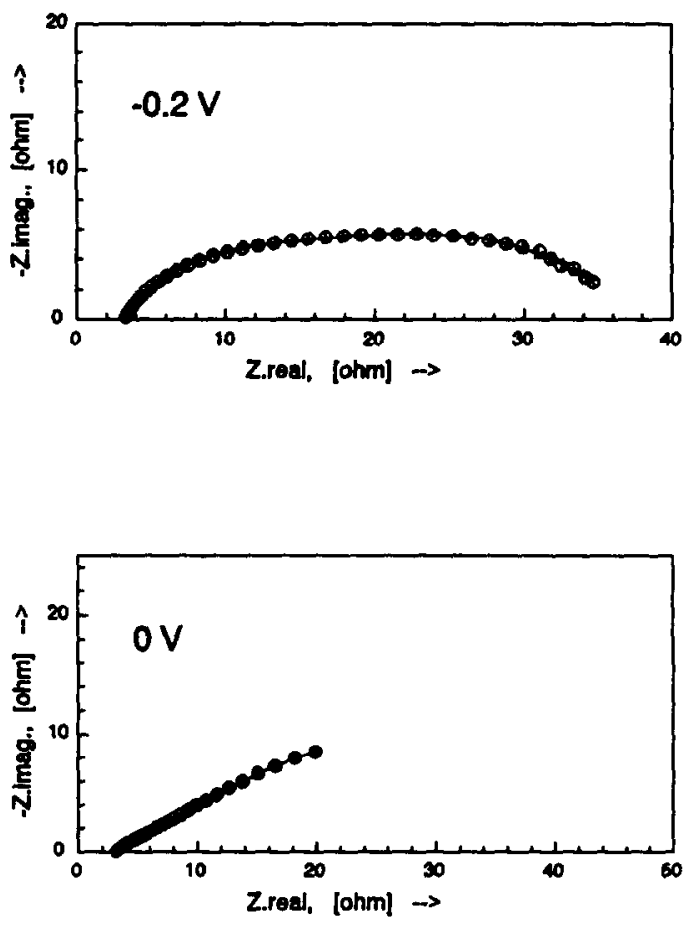


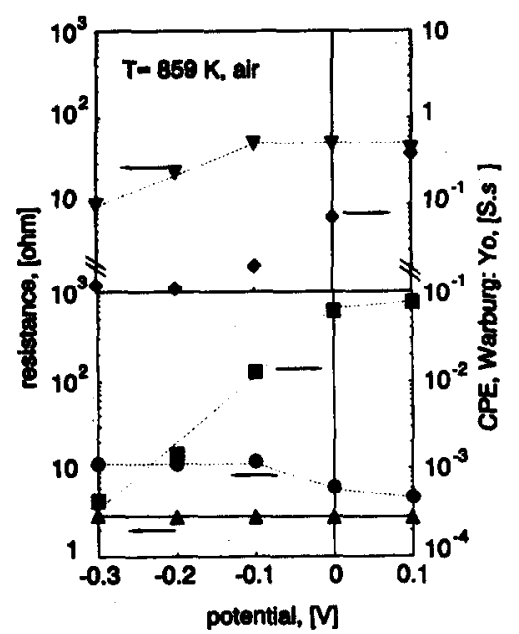

Fro. 9. Semi-log plot of the circuit parameters versus overpotential obtained from the NLLS-fit analysis of the impedance spectra (Fig. 8) of the Au $\mathrm{Au}_{\text {and }}$ BE2s electrode system. Lower plot: ( $\triangle) R_{1},(O) R_{2},(\square) C P E_{2}: Y_{0}$ value. Upper plot: ( $\bullet) R_{3},(V) C P E_{3}$ (Warburg): $Y_{0}$ value. Drawn lines serve as guide to the eye.

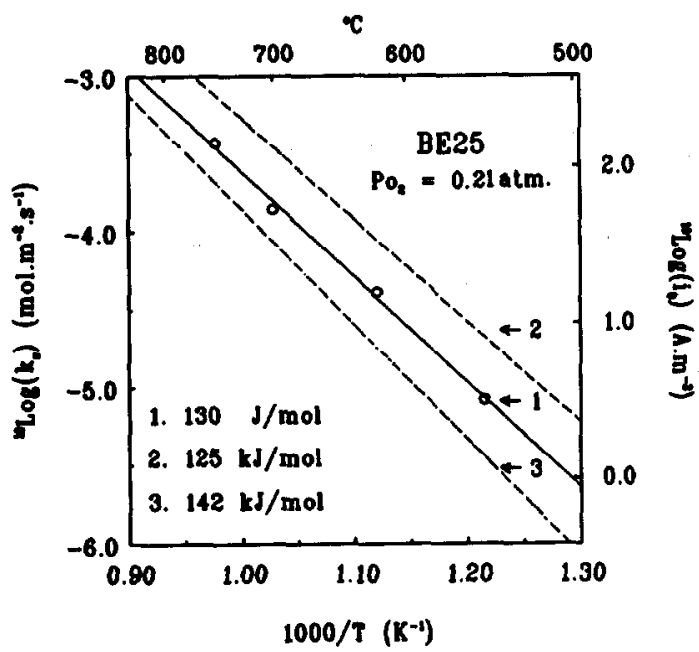

F10. 10. Arrhenius plot of the exchange current densities for the $A u_{9 p 011} / B E 25$ and the $A u_{\text {mued }} / B E 25$ electrode systems compared with the surface oxygen exchange rate, $r_{\mathbf{z}}$.

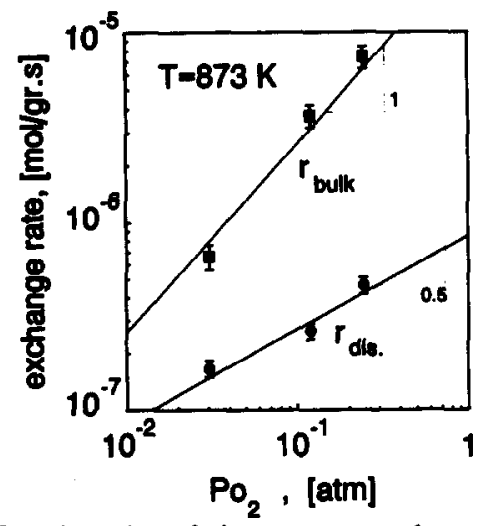

Fio. 11. Log-log plot of the separate exchange reaction rates, $r_{\text {dit }}$ and $r_{\text {bult }}$, verous $P_{\mathrm{O}_{2}}$, measured on coarsely ground BE25 at $873 \mathrm{~K}$. electrode. No inductive effects are observed for cathodic polarizations, but at anodic polarizations above $0.1 \mathrm{~V}$ a distinct inductive effect is seen. The important circuit parameters, obtained from the NLLS-fit using the equivalent circuit of Fig. 6, are presented in Fig. 9.

Isotope exchange. The surface oxygen exchange rate, $r_{2}$, is quite high for $\operatorname{BE25}[4,6]$. The exchange rate can be measured accurately using solid samples with a well defined surface area. This makes it possible to compare the $r$, values with the exchange current densities, $I_{0}$, using equation (2). In Fig. 10 the $I_{0}$ values for the $\mathrm{Au}_{\text {sput. }}$ and the $\mathrm{Au}_{\text {gnuze }}$ are presented together with the $r$, values obtained from ${ }^{18} \mathrm{O}$-exchange experiments using solid specimens. A quite reasonable match is found between the oxygen exchange rate and the exchange current density for the gauze electrode. The activation energies are almost identical.

The dissociative adsorption rate, $r_{\text {dis }}$, and the bulk transfer rate, $r_{\text {bulk }}$, of the oxygen exchange reaction were measured on crushed BE25 material[7, 24]. These preliminary investigations indicate $a\left(\boldsymbol{P}_{\mathrm{O}_{2}}\right)^{1 / 2}$ dependence for $r_{\mathrm{dis}}$ and a $\boldsymbol{P}_{\mathrm{O}_{2}}$ dependence for $\boldsymbol{r}_{\text {bulk }}$ (Fig. 11). For $P_{\mathrm{O}_{2}}=1 \mathrm{~atm}$ the dissociative adsorption is the rate determining step, but for decreasing $P_{\mathrm{O}_{2}} \boldsymbol{r}_{\text {bulk }}$ will become rate limiting.

\section{DISCUSSION}

\section{Yttria stabilized zirconia}

It is remarkable that the overall shape of the $d c$ and the ac electrode response does not change upon surface modification of the electrolyte by Feimplantation. The main difference is the increase in the exchange current density (decrease in the electrode resistance) up to a factor of 50. The shapes of the polarization curves (Fig. 1) are almost identical. The same holds for the impedance spectra, even under polarization[10]. An extra dispersive subcircuit was observed (Fig. 3) for the $\mathrm{O}_{2,8}, \mathrm{Au} / \mathrm{Fe}$ YSZ electrode system, but most likely it is not connected to the electrode reaction (see Materials and Sample Preparation, Impedance Spectroscopy).

For porous $\mathrm{Pt} / \mathrm{stabilized} \mathrm{zirconia} \mathrm{electrodes}$ several reaction models have been proposed. They are based on Langmuir type adsorption of molecular and/or dissociated oxygen on the Pt-electrode surface. Mizusaki et al.[25] ignore the charge transfer process, assuming it to be very fast. The resulting polarization relation shows current limitation at moderate overpotentials, unlike the Butler-Volmer behaviour observed here. Wang and Nowick[2] and Robertson and Michaels[3] consider the simultaneous diffusion and charge transfer of oxygen species in the interface region between the electrode and electrolyte. For a diffusion controlled electrode reaction a Butler-Volmer type polarization relation is obtained with apparent charge transfer coefficients of $\alpha_{c}=0.5$ and $\alpha_{\mathrm{a}}=1.5$, but it is unlikely that this model can predict inductive loops in the impedance diagram. A detailed discussion of these models is presented in refs $[12,26]$.

Recently Velle et al.[27] showed in a thorough impedance analysis study that surface diffusion of oxygen on $\mathrm{Pt}$, and the possible formation of $\mathrm{PtO}_{\mathbf{x}}$ 
compounds may form the rate determining reaction steps. For the last model an impedance relation has been derived, but it does not lead to inductive effects at cathodic potentials.

The occurrence of inductive loops, under cathodic polarization, is a known phenomena in wet electrochemistry, see eg[28]. It can be modeled by a two step electron transfer process where the intermediate species compete for adsorption sites. In analogy a kinetic reaction model has been developed for the $\mathrm{O}_{2,8}, \mathrm{Au} / \mathrm{YSZ}$ electrodes, which incorporates two adsorbed oxygen species[12, 26]. The sequence of electrode reaction steps is given by:

$$
\begin{aligned}
& \mathrm{O}_{2,8}+S_{\mathrm{ad}} \stackrel{\mathrm{kad}_{\mathrm{kda}}}{\rightleftharpoons} 2 \mathrm{O}_{\mathrm{ad}} \\
& 2 \times\left(\mathrm{O}_{a d}+\mathrm{e}^{\prime} \stackrel{k_{\mathrm{k} 2}}{\rightleftharpoons} \mathrm{O}_{\mathrm{ad}}^{-}\right) \\
& 2 \times\left(\mathrm{O}_{\mathrm{ad}}^{-}+\mathrm{V}_{\mathrm{o}}^{*}+\mathrm{e}^{\prime} \underset{\mathrm{k}_{03}}{\stackrel{k_{13}}{\rightleftharpoons}} \mathrm{O}_{0}^{\times}+S_{\mathrm{zd}},\right.
\end{aligned}
$$

where $S_{\text {dd }}$ represents an oxygen adsorption site. For simplicity, Langmuir type adsorption is assumed with the $O_{z d}$ and $O_{z d}^{-}$species competing for adsorption sites. For the rate constants Tafel-law behaviour is assumed:

$$
\begin{aligned}
K_{r i} & =K_{r i}^{0} \exp \left(-\beta_{i} n_{i} F \eta / R T\right) \\
K_{0 i} & =K_{0 i}^{0} \exp \left(\left(1-\beta_{i}\right) n_{i} F \eta / R T\right),
\end{aligned}
$$

where $\beta_{i}$ is the asymmetry factor and $n_{i}$ the number of electrons transfered.

For the case that charge transfer is the rate limiting process a dispersion relation can be derived[12, 26]. Following the theory of Bockris and Reddy[1] the shape of the polarization curve can be derived

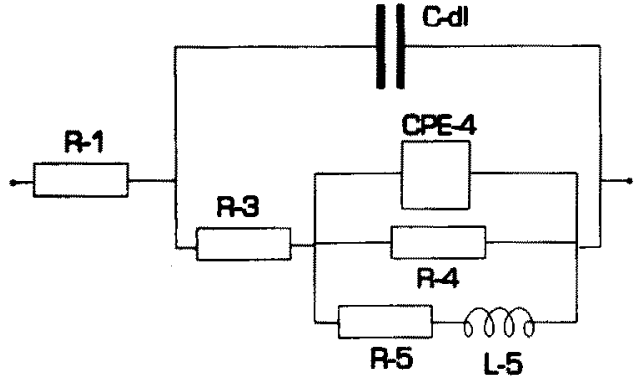

F1G. 13. Equivalent circuit which follows from the proposed stepwise charge transfer model.

from the reaction equations (equation 4). If the second reaction step is the rate limiting process then this will lead to charge transfer coefficients (equation 1) of $\alpha_{c}=0.5$ and $\alpha_{\mathrm{a}}=1.5$. The cathodic coefficient coincides well with the observed values. The measured anodic values are, however, larger than the predicted 1.5.

Using experimental data from the $d c$ polarization and the impedance measurements it was possible to generate a set of parameters with which the general shape of the impedance spectra could be reproduced[26] (Fig. 12). The equivalent circuit which models the simulated impedance spectra is presented in Fig. 13. Direct comparison of the theoretical model with the measured data is not possible as the equivalent circuit of Fig. 13 is not compatible with the equivalent circuit (Fig. 3) used in the NLLSfit data analysis. One must realize, however, that it is quite likely that diffusional steps occur simultaneously with the charge transfer steps. Due to the inherent complexity, this has not been included in
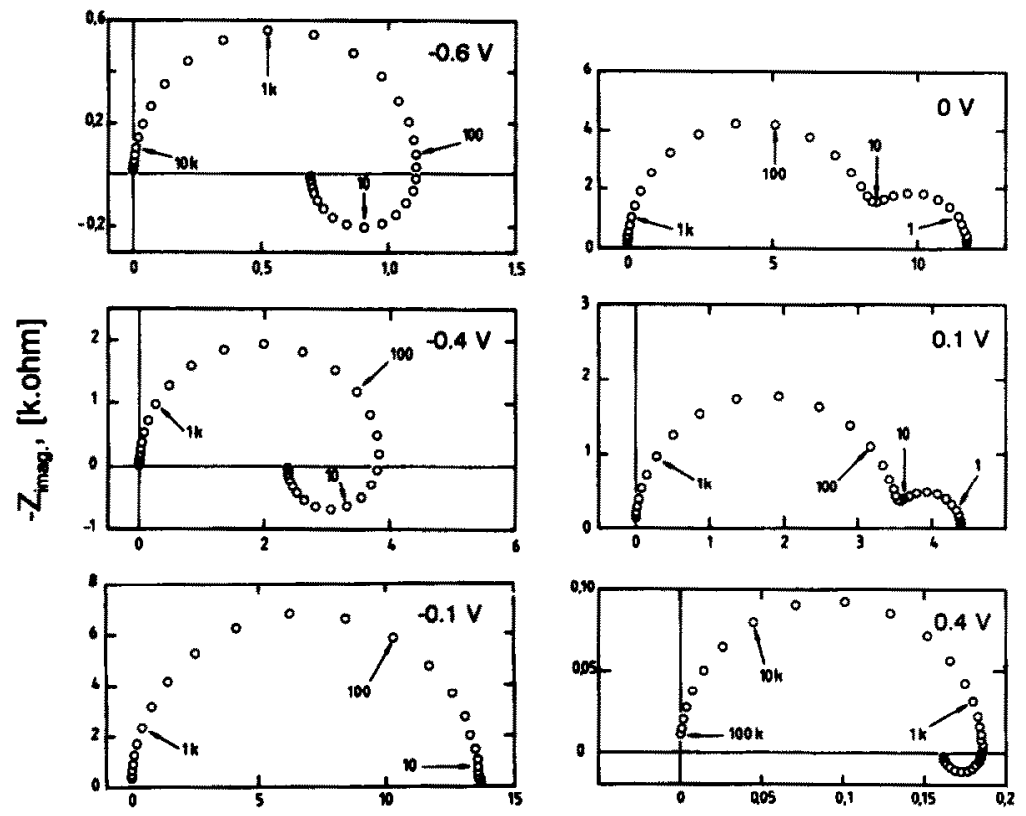

\section{$Z_{\text {reali }}$ [k.ohm]}

Fig. 12. Impedance spectra calculated with the proposed stepwise charge transfer model, as function of polarization. Parameters used are presented and discuseed in ref. [26]. frequencies are in $\mathrm{Hz}$. 


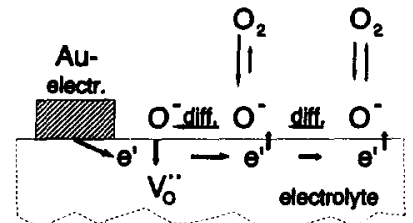

Fig. 14. Schematic representation of the flow of the electrode reaction intermediates due to a cathodic polarization for the $A u_{\text {sauxe }} / \mathrm{BE} 25$ system. Diffusion of $\mathrm{O}_{\text {ad }}^{-}$species is denoted by "diff." and an arrow.

the model development. As the charge transfer reactions will take place at the electrolyte surface over an area extending out from the gold electrode diffusion of the adsorbed oxygen species will take place, as is indicated by the observation of a (negative) Warburg-like CPE in the NLLS-fit data analysis.

As only the exchange current density increases by a factor of up to 50 upon Fe-implantation, while the electrode reaction seems to remain unchanged, it is plausible that the active electrode area increases upon Fe-implantation. A small increase in the electronic conductivity will increase the distance over which adsorbed oxygen species can diffuse to a reaction site. On the other hand, the increased surface oxygen exchange rate, observed for the Fe-implanted sample in the ${ }^{18} \mathrm{O}$-exchange experiments, can be interpreted as an effective increase in the concentration of reaction sites at the surface, which again would lead to an increase in the electrode reaction rates.

\section{Erbia stabilized $\delta$-bismuth oxide}

The almost identical exchange current densities obtained for the porous sputtered $\mathrm{Pt}$ and $\mathrm{Au}$ electrodes on BE25 show that, for this material, the type of electrode material has little effect on the oxygen transfer reaction, quite in contrast with what is observed for the zirconias. Also one must conclude that the electrode reaction is not restricted to a small region adjacent the three phase boundary line, as the relative TPB length is 14 times larger (Table 1) for the Pt electrode than for the gold electrode.

Remarkable is the increase by a factor of four to five in $I_{0}$ going from porous sputtered gold to copressed gold gauze (see Fig. 10). This roughly corresponds to the increase in the electrolyte surface area directly exposed to the gas phase by a factor of four (Table 1). Comparing the exchange current densities with the surface oxygen exchange rate (Fig. 10), using equation (2), one must conclude that the entire electrolyte surface (within the macroscopic electrode boundaries) is active in the oxygen electrode reaction.

This, however, implies that the surface of BE25 must be electronically conductive. Recent results on oxygen permeation in BE25[29] indeed showed a significant p-type electronic conduction, although the, calculated, ionic transference number remains close to unity $t_{1}=0.992$ at $973 \mathrm{~K}$ and $t_{\mathrm{i}}=0.987$ at $1038 \mathrm{~K}$ ). Preliminary measurements also indicated an enhanced (electronic) surface conductivity for BE25[24].
The interpretation of the impedance spectra is, however, more complicated. From the ${ }^{18} \mathrm{O}$ exchange measurements strong indications are found for the formation of $\mathrm{O}_{2 \mathrm{~d}}^{-}$species as rate determining step in the exchange $[7,24]$. The number and nature of the preceding steps is not yet known, but one possible route is represented by:

$$
\begin{aligned}
\mathrm{O}_{2, \mathrm{z}}+S_{\mathrm{ad}}+\mathrm{e}^{\prime} & =\mathrm{O}_{2, \text { ad }}^{-} \\
\mathrm{O}_{2, \mathrm{ad}}^{-}+S_{\mathrm{ad}}+\mathrm{e}^{\prime} & \rightleftharpoons 2 \mathrm{O}_{\mathrm{ad}}^{-} \text {(rds) }
\end{aligned}
$$

followed by:

$$
2 \times\left(\mathrm{O}_{\mathrm{ad}}^{-}+\mathrm{V}_{0}^{-*}+\mathrm{e}^{\prime} \rightleftharpoons \mathrm{O}_{0}^{\times}+S_{\mathrm{ad}}\right),
$$

which implies the presence of two different charged and mobile oxygen species which will diffuse across the surface under influence of a gradient in their respective concentrations. The charge transfer will take place across the entire electrolyte surface. It then seems plausible to attribute the two parallel $R-C P E$ sub-circuits to this kind of electrode processes. This tentative model also indicates the absence of a double layer capacitance.

The magnitudes, $Y_{0}$, of the CPE-elements, using the admittance expression $Y(\omega)=Y_{0} .(j \omega)^{n}$, are about a factor 10 larger for the $\mathrm{Au}_{\text {anuze }}$ electrode than for the $\mathrm{Au}_{\text {sput. }}$ electrodes. For the gauze electrode the maximum diffusion length is about $120 \mu \mathrm{m}$ (half the distance between two wires) while for the sputtered electrode it is about $5 \mu \mathrm{m}$ (typical diameter of a hole in the gold electrode is $10 \mu \mathrm{m}$ ), which may explain the observed difference. A finite length diffusion element ("hyperbolic cotangent" function in the admittance representation $[9,19])$ is not observed as the diffusion is not terminated by a fixed oxygen activity at the centre of the open electrolyte area.

Based on these observations the following tentative model may be considered. The exchange fluxes (equation 6) are in equilibrium at zero bias. When a cathodic polarization is applied electrons will flow from the gold electrode into the electrolyte, emanating outward along the surface. This will push the exchange reactions (equation 6) to the right. This is partially visualized in the simplified model of Fig. 14. Here only $\mathrm{O}_{\text {ad }}^{-}$is considered for clarity. Close to the electrode the exchange reactions will be affected most. Hence gradients in the concentrations of the adsorbed oxygen species will evolve, resulting in diffusion of the adsorbed species. Charge transfer will take place over the entire area, with the highest current flux close to the gold electrode. Figure 9 seems to indicate a cross-over in the rate determining step at about $-0.1 \mathrm{~V}$, similar the change in the rate determining step observed in the isotope exchange (Fig. 11), but without a mathematical model this remains highly speculative. The inductive loops at anodic polarizations $>0.1 \mathrm{~V}$ can tentatively be interpreted as a "pile up" of one adsorbed intermediate.

\section{CONCLUSIONS}

The interrelation between surface oxygen exchange measurements and electrochemical imped- 
ance and polarization measurements is clearly demonstrated. The surface oxygen exchange rate and the electrode polarization are strongly dependent on the presence of electronic (surface) conductivity.

The surface of yttria stabilized zirconia shows little surface exchange activity, as can be seen from the electrode polarization. Surface modification by $\mathrm{Fe}$ implantation not only provides some mixed conductivity in a thin surface layer, but the density of reaction (exchange) sites increases also.

While the polarization curves of erbia stabilized $\delta$-bismuth oxide are similar in shape to $\mathrm{Au} / \mathrm{YSZ}$ ones, the impedance spectra are quite different. Qualitative analysis shows that the oxide surface is highly active in the exchange process, resulting in strong diffusional effects in the electrode impedance.

The combination of techniques is not only useful for the study of the electrode properties of solid electrolytes/inert electrodes combinations, but also for the study of the electrode properties of overlayers of mixed conducting oxides such as certain perovskites.

Acknowledgements-The investigations were supported by the Netherlands Foundation for Chemical Research (SON) with financial aid from the Netherlands Organisation for Scientific Research (NWO).

\section{REFERENCES}

1. J. O. M. Bockris and A. K. N. Reddy, Modern Electrochemistry Vol. 2, Chap. 9. Plenum Press, New York (1970).

2. D. Y. Wang and A. S. Nowick, J. electrochem. Soc. 128, 55 (1981).

3. N. L. Robertson and J. N. Michaels, AIChE (Symp. Ser. $254) 83,56$ (1987).

4. B. A. Boukamp, I. C. Vinke, K. J. de Vries and A. J. Burggraaf, Solid State Ionics 32/33, 918 (1989).

5. B. C. H. Steele, J. A. Kilner, P. F. Dennis, A. E. McHale, M. van Hemert and A. J. Burggraar, Solid State Ionics 18/19, 1038 (1986).

6. B. A. Boukamp, K. J. de Vries and A. J. Burggraaf, in Non-Stoichiometric Compounds, Surfaces, Grainboundaries and Structural Defects (Edited by J. Nowotny and W. Weppner), p. 299. Kluwer (1989).

7 B. A. Boukamp, J. Verweij and A. J. Burggraaf in Solid State Ionics III (Edited by G.A. Nazri, J.-M. Tarascon and M. Armand) Vol. 293 (in press).

8. J. R. Macdonald and L. D. Potter, Jr., Solid State Ionics 23, 61 (1987).
9. B. A. Boukamp, Equivalent Circuit, internal report CT89/214/128, University of Twente (1989).

10. B. A. Boukamp, B. A. van Hassel and A. J. Burggraaf, Symposium on High Temperature Electrode Materials and Characterization (Edited by D. D. Macdonald and A. C. Khandkar), p. 44. Electrochem. Soc. Proc. Vol. 91-6 (1991)

11. S. P. S. Badwal and F. T. Ciacchi, Solid State Ionics 18/19, 1054 (1986).

12. B. A. van Hassel, Transport and Oxygen Transfer Properties of Ion Implanted Yttria Stabilized Zirconia, Ph.D. Thesis, University of Twente, The Netherlands (1990).

13. B. A. van Hassel and A. J. Burggraaf, Appl. Phys. A53, 155 (1991).

14. B. A. van Hassel and A. J. Burggraaf, Appl. Phys. A52, 410 (1991).

15. B. A. van Hassel and A. J. Burggraaf, Solid State Ionics 57, 193 (1992).

16. H. Kruidhof, K. Seshan, B. C. Lippens Jr., P. J. Gellings and A. J. Burggraaf, Mater. Res. Bull. 22, 1635 (1987).

17. B. A. van Hassel, B. A. Boukamp and A. J. Burggraaf, Solid State Ionics 48, 155 (1991).

18. B. A. van Hassel, B. A. Boukamp and A. J. Burggras,, Solid State Ionics 51, 161 (1992).

19. B. A Boukamp, Equivalent Circuit, internal report CT89/214/128, University of Twente (1989).

20. B. A. van Hassel, B. A. Boukamp and A. J. Burggraaf, presented at the 8th Int. Conf. on Solid State Ionics, Solid State Ionics 53-56, 890 (1992).

21. B. A. Boukamp, I. C. Vinke, K. Seshan, K. J. de Vries and A. J. Burggraaf, Solis State Ionics 28-30, 1187 (1992).

22. I. C. Vinke, B. A. Boukamp, K. J. de Vries and A. J. Burggraaf, Solid State Ionics 51, 249 (1992).

23. I. C. Vinke, B. A. Boukamp, K. J. de Vries and A. J. Burggraaf, Solid State Ionics 58, 33 (1992)

24. I. C. Vinke, Electrochemical and Electrode Properties of Stabilized Bismuth-oxide Ceramics, Ph.D. Thesis, University of Twente, The Netherlands (1991).

25. J. Mizusaki, K. Amono, S. Yamauchi and K. Fueki, Solid State Ionics 22, 313, 323 (1987).

26. B. A. van Hassel, B. A. Boukamp and A. J. Burggraaf, Solid State Ionics 48, 139 (1991)

27. O. J. Velle, T. Norby and P. Kofstad, Solid State Ionics 47, 161 (1991).

28. D. D. Macdonald, Symposium on High Temperature Electrode Materials and Characterization (Edited by D. D. Macdonald and A. C. Khandkar), p. 1. Electrochem. Soc. Pro. Vol. 91-6 (1991).

29. H. J. M. Bouwmeester, H. Kruidhof, P. J. Gellings and A. J. Burggraaf, presented at the 8th Int. Conf. on Solid State Ionics, Solid State Ionics 53-56, 460 (1992). 